\title{
Difference in drug cost between private and public drug plans in Quebec, Canada
}

\author{
Chamoun M. ${ }^{1,2}$, Forget A. ${ }^{1,2}$, Chabot I. ${ }^{1}$, Schnitzer M. ${ }^{1}$ and Blais L. ${ }^{1,2,3^{*}}$
}

\begin{abstract}
Background: We expect a difference in drug cost between private drug plans and the Public Drug Plan (PDP) because the dispensing fee is fixed and regulated by the PDP for publicly insured patients, whereas it is determined freely by the pharmacy owner for privately insured patients. This study compared the drug cost of Quebec residents covered by private drug plans with those covered by PDP.

Methods: We used a sample of prescriptions filled between 1 January 2015 and 23 May 2019 selected from reMed, a database of Quebecers' drug claims. We created strata of prescriptions filled by privately insured patients and matched them with strata of prescriptions filled by publicly insured patients based on the Drug Identification Number, quantity dispensed, number of days of supply, pharmacy identifier, and a date corresponding to the publication of List of Medications of Régie de l'Assurance Maladie du Québec. The differences in drug cost between private plans and the PDP were analyzed with linear regression models using prescription strata as the unit of analysis.
\end{abstract}

Results: Based on 38896 prescription strata, we observed that privately insured patients payed $\$ 9.35$ (95\% confidence interval [Cl]: $5.58 ; 13.01)$ more on average per drug prescription than publicly insured patients, representing a difference of $17.6 \%$.

Conclusions: This study showed that, on average, drug cost is substantially higher for privately insured Quebecers. Knowing that adherence to treatment is affected by drug cost, these results will help public health authorities to make informed decisions about drug policies.

Keywords: Drug insurance, Drug plan, Drug cost difference

\section{Introduction}

Since 1997, every Quebec resident has been required to have prescription drug insurance coverage at all times. There are two types of insurance plan: the Public Drug Plan (PDP), which is administered by the Régie de l'Assurance Maladie du Québec (RAMQ), and private plans (group insurance or employee benefits plans) [1]. Individuals and their family eligible for a private plan must join that plan. As of 2018, approximately $45 \%$ of Quebecers were not eligible for private coverage, were older than 65 years, or had access to Social Assistance

*Correspondence: lucie.blais@umontreal.ca

1 Faculty of Pharmacy, Université de Montréal, Montreal, QC, Canada

Full list of author information is available at the end of the article and Social Solidarity, and thus where covered by the PDP [2]. Direct patient contributions to payment of the covered drugs they purchase vary by type of drug plan; i.e., patients covered by the PDP pay a monthly deductible of $\$ 21.75$ plus $37.0 \%$ of the cost of each prescription filled as copayment, up to a maximum monthly contribution of $\$ 93.08$ (\$1 117 per year). After reaching the maximum contribution, covered drugs are free of charge until the end of the month. Privately insured patients pay a yearly deductible ranging from $\$ 0$ to $\$ 100$ and a copayment of $0 \%$ to $37 \%$, with a maximum yearly contribution of $\$ 1$ $117[3,4]$. After reaching the maximum contribution, the covered drugs are free of charge until the end of the year.

Drug cost in Quebec has three components: ingredient list price, wholesaler mark-up, and dispensing fee. 
The first two components are regulated by the RAMQ and are the same for patients covered by the PDP or by private drug plans. The third component is fixed by the RAMQ (between $\$ 8.50$ and $\$ 9.49$ ) for beneficiaries of the PDP. For patients covered by private drug plans, the dispensing fee is not regulated and is established by pharmacy owners to promote business profitability. Therefore, the drug cost is the same in all pharmacies for patients covered by the PDP, but may vary among pharmacies for patients covered by a private drug plan $[1,5]$.

Drug cost has been identified as a barrier to adherence to prescribed treatment [6]. Patients who spend more than USD 100 per month for drugs are 5.57 times more likely to be non-adherent than patients who spend less than USD 50 per month $(p<0.001)$ [7]. Low adherence is associated with lower treatment efficacy, disease complications, and increase in health care expenditure [6]. In the United States and Canada, non-adherence is estimated to cost annually to the healthcare systems USD 100 billion and CAD 4 billion, respectively $[8,9]$.

According to the studies conducted in the United States and Canada, including the province of Quebec, the average drug cost is between 13 and 70\% higher for privately insured patients than publicly insured patients [10-18]. However, the methodological limitations of previous studies and reports prevent us from drawing reliable conclusions from the reported wide range of differences in drug cost. These limitations include small sample size, the analysis of only one drug or one class of drugs, and failure to assess whether the observed differences are statistically significant or whether they are due to hazard. Finally, the previous studies compared patients with private and public drug insurance who had purchased different drugs with different quantities dispensed, formulations, and numbers of days supplied, and so may have reported confounded cost differences.

The overarching aim of the study is to provide a portrait of drug costs for Quebec residents covered by private and public drug plans to patients, healthcare professionals and decision makers. The primary objective was to estimate the average difference in drug cost between patients covered by private drug plans and the PDP in Quebec. We used provincial electronic prescription records and a design that minimizes confounding by directly contrasting the purchase of identical drugs between private dug plans and the PDP. The secondary objective was to estimate the average difference in drug cost separately for generic and innovator (or brand name) drugs between patients covered by private drug plans and those covered by the PDP.

\section{Methods}

\section{Source of data}

This study was performed using the Registre de données sur les médicaments (reMed) database and all methods were performed in accordance with the relevant guidelines, regulations and approved by an appropriate ethics committee. This database includes longitudinal patientlevel claims data for prescriptions filled at community pharmacies by a sample of Quebec residents enrolled in community pharmacies, medical clinics, or blood test facilities from different regions of Quebec since 2008. At enrollment, participants were covered by a private drug plan and had to be age $<65$ years. Patients were kept in the database if they switched to the PDP or reached the age of 65 years. The data, including drug name, formulation, dose, quantity dispensed, Drug Identification Number (DIN; a unique identifier of all drug products sold in a specific dosage form in Canada), date of prescription being filled, number of days supplied, drug insurance type (private or PDP), anonymized pharmacy identifier, and drug cost, can be retrieved from reMed $[19,20]$.

\section{Study design and outcome}

A stratified cross-sectional design was used to fulfill the objectives. Before creating the strata, all prescriptions filled between 1 January 2015 and 23 May 2019 by privately insured patients registered in reMed were selected. We excluded filled prescriptions with invalid DIN or drug insurance number, drug cost or quantity equal to zero, inconsistency between cost and quantity dispensed, or patient age $\geq 65$ years. Then, we formed strata of prescriptions with the same DIN, quantity dispensed, number of days supplied, pharmacy identifier, and edition of RAMQ's List of Medications in force at the time of prescription dispensation to establish the ingredient list price. The RAMQ's List of Medications sets out all prescription drugs covered by the PDP and their condition of coverage, including ingredient list price and is updated regularly to include new drugs and revised prices. A total of 38 updated editions of the RAMQ's List of Medications were published over the study period. We created a unique number for each version of RAMQ's List of Medications (i.e., 38 numbers) according to the period of time when the list was in force and we linked each prescription to the relevant list by using the date when the prescription was filled. Finally, each stratum of prescriptions filled by privately insured patients was matched with a stratum of prescriptions filled by patients insured by the PDP based on the same stratification factors. By matching on the number of the RAMQ's List of Medications we controlled for the seniority of drugs by design. Our stratified design minimizes confounding in the quantification of the difference in drug cost between private drug plans 
and the PDP because the stratification factors are known to determine drug cost $[1,21-23]$.

The outcome was the drug cost, defined as the sum of the ingredient list price, wholesaler markup, and dispensing fee. As stated in the introduction, in Quebec the first two components of the drug cost are regulated by the RAMQ and are the same for patients covered by the PDP or by private drug plans, while dispensing fees may vary between drug plans.

\section{Statistical analyses}

Descriptive analyses were used to summarize the characteristics of the study patients. The proportions of patients covered only by the PDP, only by a private drug plan, and who switched drug plan during the study period were calculated. Distributions of patients' sex, age when the last prescription was filled, and year of enrollment were described using proportions. The mean and standard deviation (SD) of: the number of drug prescriptions filled, number of different molecules filled and number of pharmacies visited during the study period were calculated. Moreover, the total number of molecules and DINs in the sample, and the mean and standard deviation of the number of prescriptions per stratum were calculated.

To meet our objective, we estimated the mean drug cost separately for private drug plans and the PDP, using the strata as the unit of analysis. Then, we calculated two means: one mean of the means of drug cost for all private drug plan strata and one for all the PDP strata. This was done for all drugs in the sample. We then performed similar analyses for the subsets composed of: 1) all the strata containing the 10 most frequent drug classes in the sample, 2) all the strata containing the 10 most frequent molecules in the sample, and 3) all the strata containing the 10 most expensive molecules in the sample. In addition, we plotted the relationship between ingredient list price and absolute (\$) and relative (\%) differences in drug cost between private drug plans and the PDP. To calculate the relative difference in drug cost between private drug plans and PDP, we divided the difference in drug cost by the PDP drug cost because the latter is fixed and regulated by the PDP, and thus is used as a reference in our analysis. We also estimated the intra-stratum variation of drug cost with the standard deviation of prescriptions drug cost in a stratum and we calculated the proportion of strata with a standard deviation greater than zero.

Using linear regression models and the stratum as the unit of analysis, we estimated the mean differences in drug cost between private drug plans and the PDP, while taking into account the size of the strata. The dependent variable was the mean drug cost in the stratum and the independent variable was the type of drug insurance (private or PDP). The strata were weighted according to the number of prescriptions filled by privately insured patients they contained because it is considered as an important source of potential bias. Indeed, the prevalence of use of the drugs (i.e. volume of distribution) is likely to impact the dispensing fee (i.e. drugs with low volume might lead to higher dispensing fees) and consequently the cost of the drug. The use of the regression analysis allows to control for the size of the strata and consequently to control for the potential bias associated with the prevalence of use of the drugs in the estimation of the mean difference in drug cost, its standard deviation, and its 95\% CI. By considering each filled prescription being independent of the other (i.e. not considering the strata via a regression analysis) we would have greatly under estimated the standard deviation of the mean difference in drug cost and provided smaller $95 \% \mathrm{CI}$, with the consequence of declaring differences statistically significant while they were not in reality.

To meet the secondary objective, we repeated the analyses separately for generic and innovator drugs for the 10 most frequent drug classes. Analyses were done with SAS software, version 9.4 (SAS Institute Inc., Cary, NC) and Excel (Microsoft, Redmond, WA).

\section{Results}

There were 3188963 prescriptions filled by patients covered by private drug plans between 1 January 2015 and 23 May 2019 in reMed. After excluding prescriptions with invalid DIN or drug insurance number, drug cost or quantity equal to zero, or patient age $\geq 65$ years, there were 2335846 prescriptions (Table 1). After excluding 203 additional prescriptions because of discrepancy between drug cost and quantity dispensed, we had 2335643 prescriptions and created 1636401 strata based on the DIN, quantity dispensed, number of days supplied, pharmacy identifier, and version of RAMQ's List of Medications used to establish the cost of filled prescriptions. Of these private drug plan strata, 38896 were one-to-one matched to strata of prescriptions filled under the PDP, for a total of 162019 prescriptions and 77792 strata. On average, each stratum was made of 4.2 (SD: 3.9) prescriptions. We analyzed a total of $363 \mathrm{~mol}-$ ecules and 1637 DINs. Table 2 presents an example of a stratum containing seven 30-day prescriptions of 30 tablets of Apo-Divalproex dispensed in one pharmacy and reimbursed by the PDP and a private drug plan. When considering only the 10 most frequent drug classes in the sample, the 10 most frequent molecules, and the 10 most expensive molecule subgroups, the numbers of matched strata were 29 998, 20179 , and 12 336, respectively. When generic and innovator drugs were analyzed separately for the 10 most frequent drug classes, there were 22098 and 7900 matched strata, respectively. 
Table 1 Selection of the study sample

\begin{tabular}{lll}
\hline & Private drug plan & PDP \\
\hline Filled prescriptions recorded in reMed between 1 January 2015 and 23 May 2019 & 3188963 prescriptions & 1816751 prescriptions \\
& 38064 patients & 10029 patients \\
Excluding filled prescriptions with drug cost or quantity equal to zero and invalid DIN or drug insur- & 2629317 prescriptions & 1694527 prescriptions \\
ance number & 33441 patients & 9495 patients \\
Excluding prescriptions filled by patient 65 years old or more at the date of the last filled prescrip- & 2335846 prescriptions 558273 prescriptions \\
tion & 32270 patients & 6244 patients \\
Excluding filled prescriptions inconsistency between cost and quantity dispensed & 2335643 prescriptions 557675 prescriptions \\
& 32093 patients & 6187 patients \\
Strata of prescriptions based on DIN, quantity dispensed, number of days supplied, pharmacy & 2335643 prescriptions 557675 prescriptions \\
identifier and RAMQ's List of Medications & 1636401 strata & 330827 strata \\
& 32093 patients & 6187 patients \\
Matching strata of prescriptions filled by privately insured patients to strata of prescriptions filled by & 100809 prescriptions & 61210 prescriptions \\
patients insured by the PDP (12 570 different patients in total) & 38896 strata & 38896 strata \\
& 10287 patients & 3599 patients \\
\hline
\end{tabular}

Table 2 Example of a stratum (stratum ID: 340)

\begin{tabular}{|c|c|c|c|c|c|c|}
\hline Insurance type & DIN & $\begin{array}{l}\text { Quantity } \\
\text { dispensed }\end{array}$ & $\begin{array}{l}\text { Number of days } \\
\text { supplied }\end{array}$ & $\begin{array}{l}\text { Pharmacy } \\
\text { identifier }\end{array}$ & $\begin{array}{l}\text { RAMQ's List of } \\
\text { Medications number }\end{array}$ & Cost (\$) \\
\hline Public & 02239699 & 30 & 30 & 467269 & 13 & $12 \cdot 54$ \\
\hline Public & 02239699 & 30 & 30 & 467269 & 13 & $12 \cdot 54$ \\
\hline Public & 02239699 & 30 & 30 & 467269 & 13 & $12 \cdot 54$ \\
\hline Private & 02239699 & 30 & 30 & 467269 & 13 & 14.89 \\
\hline Private & 02239699 & 30 & 30 & 467269 & 13 & 14.89 \\
\hline Private & 02239699 & 30 & 30 & 467269 & 13 & 14.89 \\
\hline Private & 02239699 & 30 & 30 & 467269 & 13 & 14.89 \\
\hline
\end{tabular}

The 162019 prescriptions included in the sample were filled by 12570 different patients. As shown in Table 3, most of the patients only had a private drug plan throughout the study period $(n=8971)$. The distributions of sex, age, and year of enrolment were similar for patients covered by the PDP, those covered by private drug plans, and those who switched drug plans during the study period. The results suggest that patients covered by the PDP throughout the study and those who switched drug plans filled more prescriptions (17.5 and 26.5 vs 9.7$)$ and used more molecules (2.6 and 3.7 vs 1.7 ) than patients privately insured throughout the study. The number of pharmacies visited was similar for all three groups of patients.

Table 4 presents the average drug cost for private drug plans and the PDP. We observed that the average drug cost was $\$ 62.34$ for private drug plans and $\$ 52.99$ for the PDP, with a crude difference of $\$ 9.35$, representing a $17.6 \%$ greater cost for private drug plans. For generic drugs, we observed an average difference of $\$ 5.77$ per prescription, or a $27.8 \%$ increase in cost in the private versus public drug plans. For innovator drugs, we observed an average difference of
$\$ 19.61$ per prescription, or a $15 \cdot 1 \%$ higher cost in the private versus the public drug plans. We found that the intra-stratum standard deviation of the drug cost was higher than zero in 4600 strata $(11.8 \%)$ of private drug plans and in 4349 strata (11.2\%) of the PDP. Among strata from private drug plans with intra-stratum variations, the mean of the intra-stratum mean drug cost was \$58.28 (SD: 273.43; Q1-Q3: 10.41-27.02) and the mean of the intra-stratum standard deviation of drug cost was \$1.30 (SD: 4.09; Q1-Q3: 0.05-1.13), indicating very small variations in drug cost within strata. Among strata from the PDP with intra-stratum variations, corresponding figures were \$48.01 (SD: 244.21; Q1-Q3: 10.15-20.29) and \$0.42 (SD: 0.75; Q1-Q3: $0 \cdot 27-0.42$ ).

Figures 1,2 and 3 present the difference in mean drug cost between private drug plans and the PDP for selected drug subgroups. The mean drug cost for the 10 most frequent drug classes was higher for drugs reimbursed by private drug plans, except for thyroid therapy where the cost for patients covered by private drug plans was $\$ 0.68$ (6.4\%) lower (Fig. 1). We observed a similar trend for the 10 most frequent molecules 
Table 3 Patients' characteristics

\begin{tabular}{|c|c|c|c|}
\hline & $\begin{array}{l}\text { Publicly insured } \\
\text { patients }^{\mathrm{a}}\end{array}$ & $\begin{array}{l}\text { Privately insured } \\
\text { patients }^{\mathrm{a}}\end{array}$ & $\begin{array}{l}\text { Privately and Publicly } \\
\text { insured patients at different } \\
\text { moments }^{\mathrm{a}}\end{array}$ \\
\hline Characteristic & n (\%) & n (\%) & n (\%) \\
\hline $\mathrm{N}$ & $2283(100)$ & $8971(100)$ & $1316(100)$ \\
\hline \multicolumn{4}{|l|}{ Sex } \\
\hline Female & $1639(71 \cdot 8)$ & $6338(70 \cdot 6)$ & $935(71 \cdot 1)$ \\
\hline Male & $644(28 \cdot 2)$ & $2633(29.4)$ & $381(28 \cdot 9)$ \\
\hline \multicolumn{4}{|l|}{ Age (years) when patients filled their last prescription } \\
\hline $0-18$ & $94(4 \cdot 1)$ & $520(5 \cdot 8)$ & $54(4 \cdot 1)$ \\
\hline $18-40$ & $598(26 \cdot 2)$ & $2707(30 \cdot 2)$ & $368(28 \cdot 0)$ \\
\hline $40-65$ & $1591(69 \cdot 7)$ & $5744(64 \cdot 0)$ & $894(67 \cdot 0)$ \\
\hline \multicolumn{4}{|l|}{ Year of enrolment in reMed } \\
\hline $2008-2014$ & $1717(75 \cdot 2)$ & $7325(81 \cdot 7)$ & $1075(81 \cdot 7)$ \\
\hline 2015-2019 & $566(24 \cdot 8)$ & $1646(18 \cdot 3)$ & $241(18 \cdot 3)$ \\
\hline Number of prescriptions filled per patient ${ }^{a}$ (mean (SD)) & $17 \cdot 5(32 \cdot 5)$ & $9.7(16 \cdot 4)$ & $26 \cdot 3(38 \cdot 7)$ \\
\hline Number of different molecules filled per patient ${ }^{\mathrm{a}}$ (mean (SD)) & $2 \cdot 6(2 \cdot 2)$ & $1 \cdot 7(1 \cdot 2)$ & $3 \cdot 7(2 \cdot 6)$ \\
\hline Number of pharmacies per patient ${ }^{\mathrm{a}}$ (mean (SD)) & $1.3(0.7)$ & $1 \cdot 2(0.4)$ & $1.5(0.8)$ \\
\hline
\end{tabular}

SD standard deviation

a During study period between 1 January 2015 and 23 May 2019

Table 4 Drug cost (\$) according to drug insurance type

\begin{tabular}{|c|c|c|c|}
\hline PDP & Private & & \\
\hline $\begin{array}{l}\text { Mean (SD) } \\
\text { (\$) }\end{array}$ & $\begin{array}{l}\text { Mean (SD) } \\
\text { (\$) }\end{array}$ & $\begin{array}{l}\text { Mean difference: private } \\
\text { versus PDP }(\$)\end{array}$ & $\begin{array}{l}\text { Mean difference: } \\
\text { private versus PDP } \\
(\%)\end{array}$ \\
\hline $52.99(393.14)$ & $62 \cdot 34(444 \cdot 89)$ & $9 \cdot 35$ & $17 \cdot 6$ \\
\hline $20.78(178.08)$ & $26.55(197.44)$ & $5 \cdot 77$ & $27 \cdot 8$ \\
\hline $129.66(563.84)$ & $149 \cdot 26(656 \cdot 60)$ & 19.61 & $15 \cdot 1$ \\
\hline
\end{tabular}

SD standard deviation

(Fig. 2). The mean cost of the 10 most expensive molecules was higher for patients covered by a private drug plan (Fig. 3).

Figures 4 and 5 present the association between the difference in drug cost (in dollars and percentage, respectively) and the ingredient list price according to the RAMQ's List of Medications. We observed a clear positive association between the ingredient list price and the mean difference in cost expressed in dollars, with patients covered by private drug plans paying more for their drugs. The largest relative difference in drug cost between private drug plans and the PDP was $42.2 \%$ for ingredient list prices ranging between $\$ 10.00$ and $\$ 12.50$.

The regression analysis revealed that being covered by a private drug plan compared with the PDP was associated with an average increase in drug cost of $\$ 9.35$ (95\% confidence interval [CI]: $\$ 5.68$ to $\$ 13 \cdot 01$ ) (Table 5).
In addition, the cost difference expressed in dollars was much higher for innovator drugs than generic drugs.

\section{Discussion}

On average, drug cost was found to be $17.6 \%$ higher for drugs reimbursed by private insurance than by the PDP. The costs of innovator and generic drugs were $15 \cdot 1 \%$ and $27.8 \%$ higher for private drug plans compared with the PDP, respectively. However, specific drug costs can sometimes be lower under a private drug plan, as in the case of levothyroxine sodium. On the other end, drug costs for prescriptions filled in a community pharmacy can be up to $\$ 400.00$ higher for privately insured patients than patients insured by the PDP when the ingredient list price is between $\$ 2500 \cdot 00$ and $\$ 3000 \cdot 00$. In addition, our study showed that the difference in drug cost measured in dollars between private drug plans and the PDP 


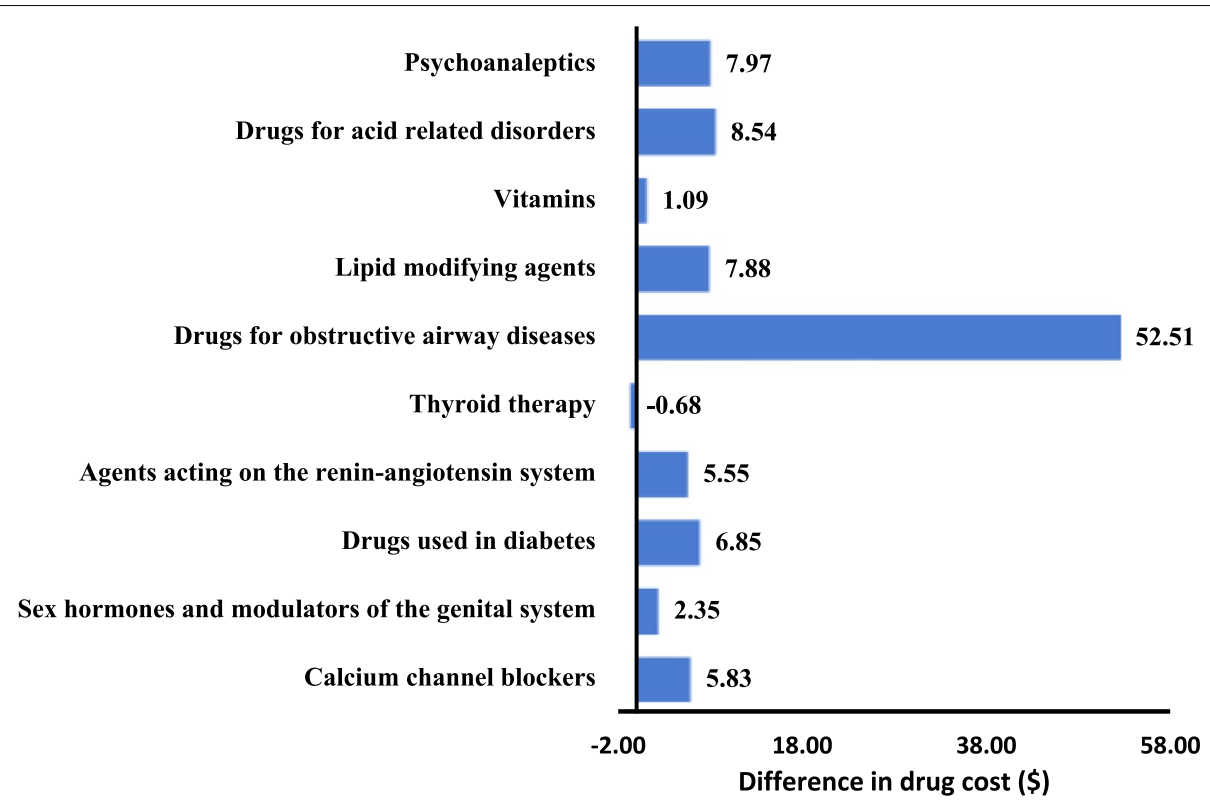

Fig. 1 Difference in drug cost (\$) private drug plans vs PDP for 10 most frequent drug classes ( $n=29998$ strata)

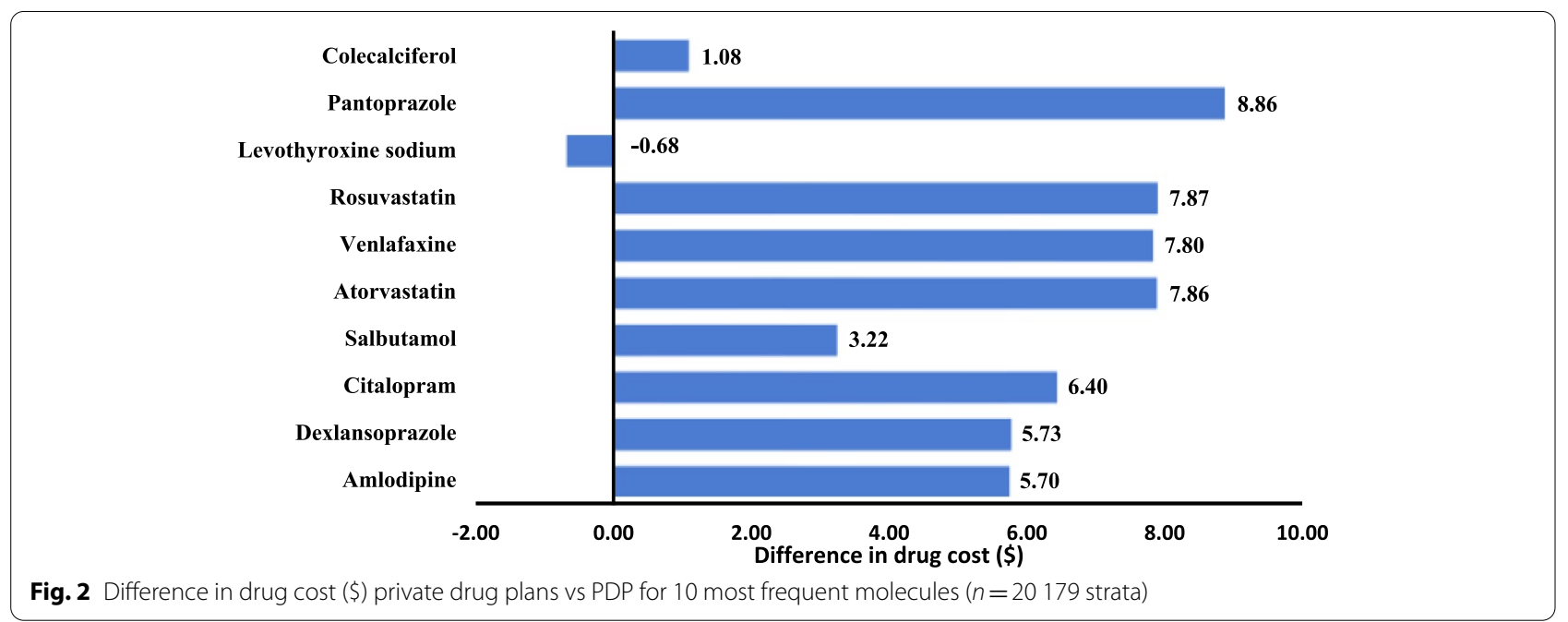

increased with the ingredient list price. However, the relative difference measured in percentage did not show the same relationship, as it increased for ingredient list prices between $\$ 5.00$ and $\$ 25.00$, and decreased thereafter.

Our results were similar to those reported by previous studies conducted in Quebec. Indeed, a study by Desgagné showed that the costs of esomeprazole as an innovator and generic drug were $12.7 \%$ and $55.9 \%$ higher, respectively, for private drug plans compared with the PDP [12, 24]. Moreover, Levert showed that the costs of innovator and generic drugs were $17.0 \%$ and $37.0 \%$ higher, respectively, for private drug plans compared with the PDP in Quebec [13]. Studies conducted outside of Quebec reported drug costs up to $70 \%$ higher for privately insured patients than publicly insured patients but the comparison with our results is difficult since the regulation of the elements of the drug cost was either different from the one in place in Quebec or not clearly reported. Moreover, previous studies had various limitations, such as a small sample size, absence of statistical analyses, or lack of information about the study design, and the distribution of molecules differed between patients covered by private and public drug plans, giving rise to a risk of bias [10-18]. 

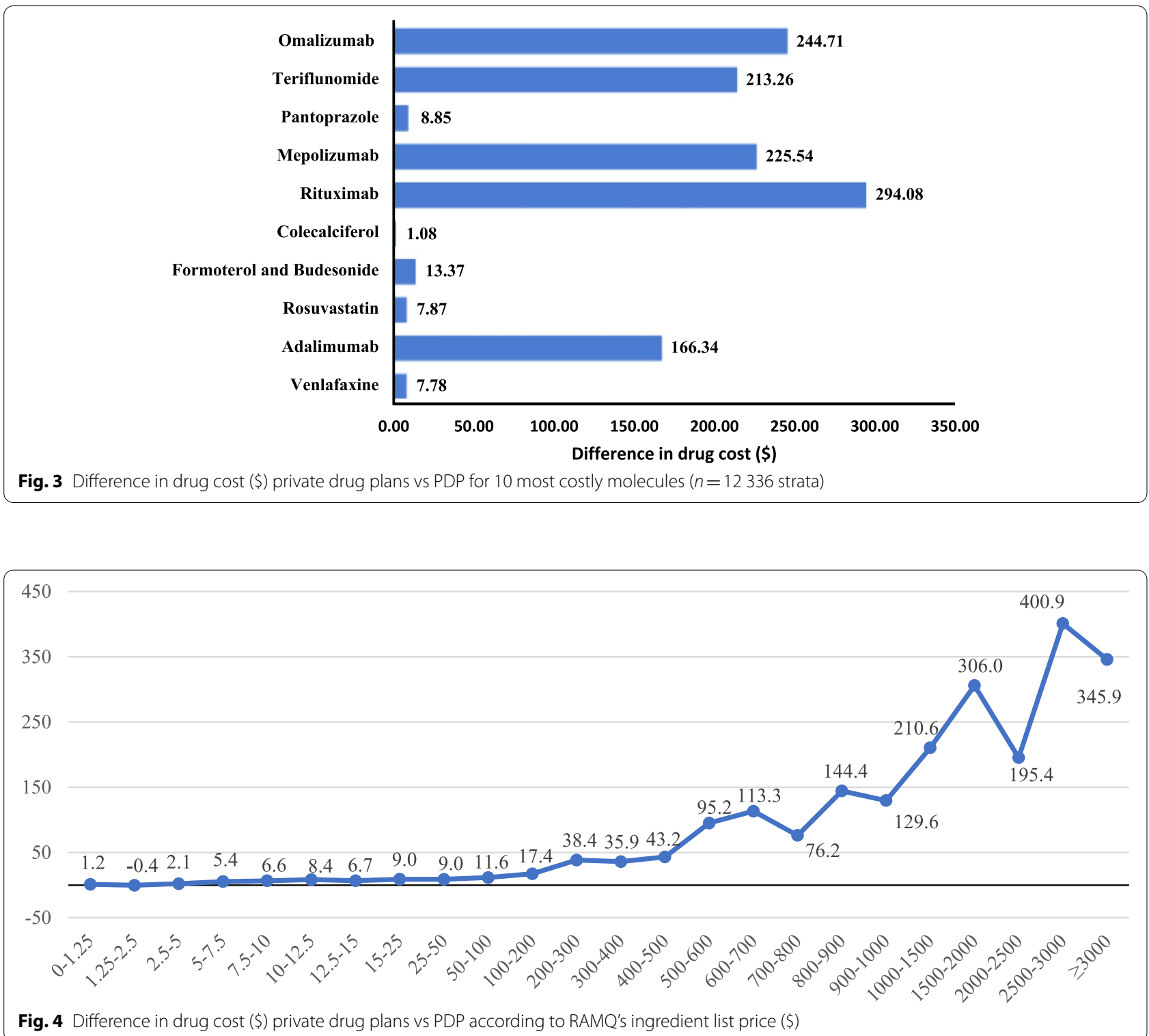

Our study has several strengths. First, we used a stratified design that minimized confounding bias in estimating the mean difference in drug cost between private drug plans and the PDP. Strata were defined according to all known and measurable factors that can influence the cost of a drug [1,21-23]. We then used linear regression models to estimate the cost difference, while taking into account the size of each stratum. Furthermore, the sample size was large (162 019 prescriptions and 77792 strata) and we analyzed 363 different molecules and 1637 unique DINs. By limiting our study population to patients $<65$ years, our study was representative of the population insured by private drug plans in Quebec.
However, the present results should be interpreted in light of the following limitations. reMed is not a random sample of patients covered by private drug plans in Quebec. The age and sex distributions are different from the population of Quebec. However, the participation in reMed is high (83\%), participants are recruited in different rural and urban areas throughout the province, and the BMI, smoking status, and most used drug classes are similar between the Quebecers covered by a private drug plan and the patients in reMed [25-30]. We observed that in $11.5 \%$ of the strata, the intra-stratum standard deviation of the mean drug cost was higher than zero, meaning that drug cost varied between prescriptions of the stratum. This suggests that we could 


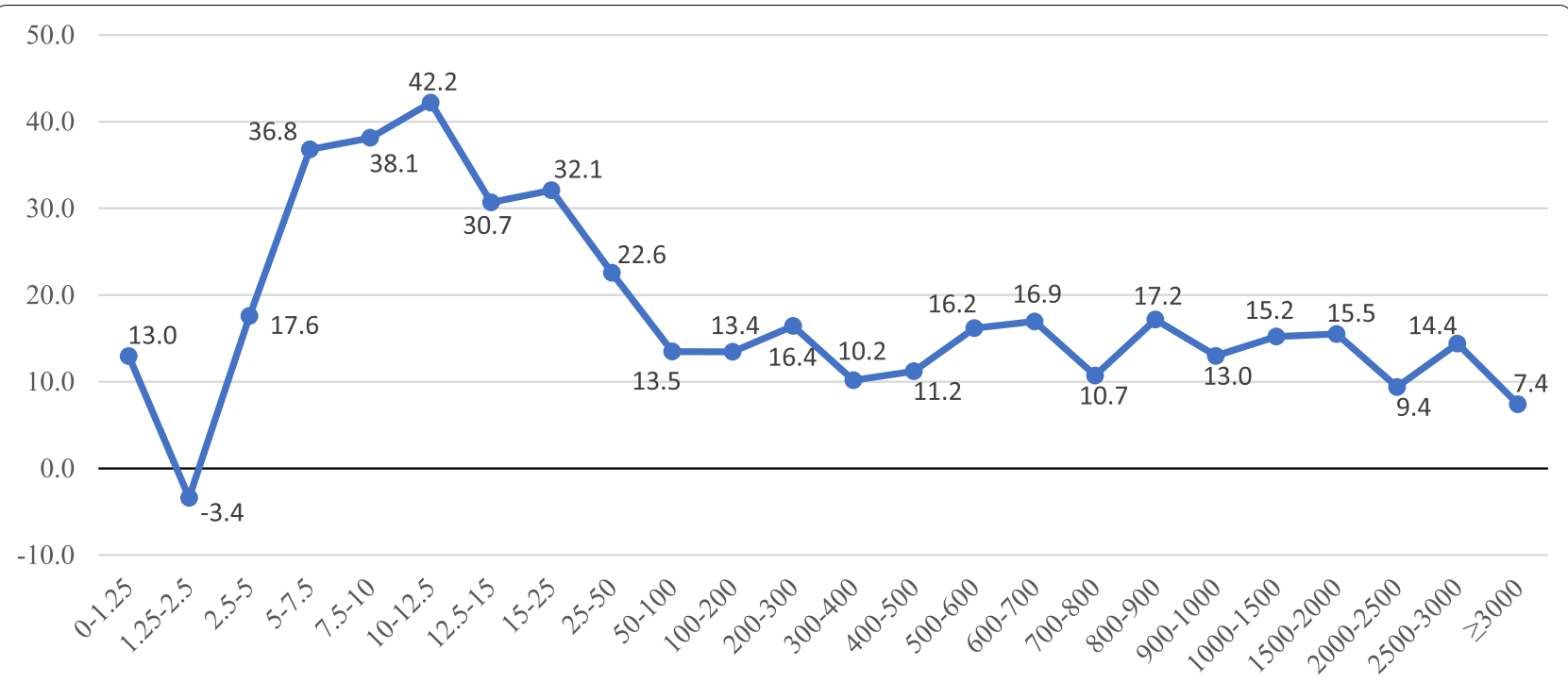

Fig. 5 Relative difference in drug cost (\%) private drug plans vs PDP according to RAMQ's ingredient list price (\$)

Table 5 Differences in drug cost (\$) according to drug insurance type, as obtained from linear regression models

\begin{tabular}{clcc}
\hline & \multicolumn{3}{l}{ Private drug plans vs PDP } \\
\hline Model (number of strata) & \multicolumn{4}{l}{ Mean difference (\$) } & 95\% Cl \\
All drugs (38 896) & 9.35 & $5.68 ; 13.01$ & \\
Generic drugs (22 098) & 5.77 & $3.74 ; 7.80$ & \\
Innovator drugs (7 900) & 19.61 & $7.01 ; 32.20$ & \\
\hline
\end{tabular}

not control for all factors that affect drug cost within a stratum, although we controlled for the main cost drivers $[1,21-23]$. This variability in cost within a stratum could be explained by data entry errors remaining despite the rigorous data quality control process in reMed. In addition, for privately insured patients, the dispensing fees can change over time. For publicly insured patients, the dispensing fees are determined yearly by government but it can change during a year based on the number of prescriptions served by the pharmacy. However, the intrastratum variation for private drug plans and the PDP was found to be low compared with the mean drug cost, suggesting that it should not meaningfully affect the validity of this study.

The difference in mean drug cost observed in our study is driven by difference in dispensing fees between the PDP and private drug plans. Factors that can contribute to the higher dispensing fees in the private drug plans include a potential underfunding of the PDP through a fixed dispensing fee that did not keep pace with inflation, the need to support a large and increasingly expensive inventory of medications and the rising pharmacy operating expenses (rent, employee salaries and benefits, equipment, etc.), that challenges the profitability of the pharmacy.

\section{Conclusion}

Our study shows that the drug cost is on average $\$ 9.35$ (17.6\%) higher for drugs reimbursed by private insurance than by the PDP, a gap driven by differences in dispensing fees between the two types of drug programs. These results inform patients, pharmacists, public health authorities and private insurers in Quebec and in Canada as well as any other decision makers managing a public drug plan about the size and the source of the drug cost differences between private insurance and PDP. They can support evidence-based decision making about drug insurance and pricing policies, as universal public drug programs and other mechanisms that aim at regulating dispensing fees and the total drug costs are debated in the political arena in several countries, including Canada. Our results could guide the development of drug plan policies and regulations that will ensure pharmacists' remuneration (including dispensing fees) reflect their skills, training, services and business expenses while decreasing inequities in the cost of drug distribution activities between the private and public sectors.

\section{Abbreviations}

PDP: Public Drug Plan; RAMQ: Régie de l'Assurance Maladie du Québec; reMed: Registre de données sur les médicaments; DIN: Drug identification number. 


\section{Acknowledgements}

CM acknowledges financial support from the Réseau Québécois de Recherche sur les Médicaments. CM acknowledges that part of the current submission was originally included in his thesis.

\section{Authors' contributions}

FA and BL contributed to the study design and analysis, and assisted in critically revising the manuscript. $\mathrm{Cl}$ assisted in critically revising the manuscript and contributed to the study design. SM contributed to the study analysis and assisted in revising the manuscript. CM conceived the study, performed the analysis, created the tables and figures, and drafted the manuscript. The author(s) read and approved the final manuscript.

\section{Funding}

This study was funded by the Réseau Québécois de Recherche sur les Médicaments. The funder had no role in study design, data collection, data analysis, data interpretation, or writing of the report. reMed was financed by the funder.

\section{Availability of data and materials}

The data that support the findings of this study are available from the reMed data extraction committee from the Université de Montréal but restrictions apply to the availability of these data, which were used under license for the current study, and so are not publicly available. Data are however available from Lucie Blais upon reasonable request and with permission of the reMed data extraction committee and the Human Scientific and Ethics Committee of the Centre Intégré Universitaire de Santé et de Services Sociaux du Nord-de-lîle-de-Montréal.

\section{Declarations}

\section{Ethics approval and consent to participate}

According to the institutional guidelines, this study was approved by the Human Scientific and Ethics Committee of the Centre Intégré Universitaire de Santé et de Services Sociaux du Nord-de-l'île-de-Montréal (reference number: 2019-1629). All reMed participants signed an informed consent form allowing the use of their drug data for future studies. For reMed's participants aged less than 16 years, an informed consent was obtained from their parent or legal guardian.

\section{Consent for publication}

Not applicable since no human identity revealing data is used in the study.

\section{Competing interests}

We declare no competing interests.

\section{Author details}

${ }^{1}$ Faculty of Pharmacy, Université de Montréal, Montreal, QC, Canada. ${ }^{2}$ Centre Intégré Universitaire de Santé Et de Services, sociaux du Nord-de-l'île-de-Montréal, Montreal, QC, Canada. ${ }^{3}$ Endowment Pharmaceutical Chair AstraZeneca in Respiratory Health, Montreal, QC, Canada.

Received: 2 June 2021 Accepted: 3 February 2022

Published online: 14 February 2022

\section{References}

1. Brigitte Milord CM. Étude sur la transparence des prix en pharmacie: Pour le groupe de travail de l'Ordre des Pharmaciens du Québec sur le sujet. 2014: Ordre des Pharmaciens du Québec. Available from: https://jbour bonnais.org/wp-content/uploads/2016/08/Étude-sur-la-transparencedes-prix-en-pharmacie.pdf.

2. Régie de l'assurance maladie du Québec. La RAMQ en quelques chiffres 2019 [cited 2019 2019-03-14]; Les statistiques qui suivent sont tirées de nos rapports annuels de gestion et mises à jour chaque année. Elles représentent la situation du 1er avril au 31 mars de l'année indiquée. Available from: http://www.ramq.gouv.qc.ca/fr/donnees-et-statistiques/ Pages/la-regie-en-quelques-chiffres.aspx.
3. Régie de l'assurance maladie du Québec. Assurance médicaments-Tarifs en vigueur. 2019 [cited 2019 2019-03-14]; Les tarifs en vigueur pour le régime public d'assurance médicaments sont ajustés chaque année le 1er juillet. Certaines personnes sont assurées sans frais. Le pharmacien est informé des tarifs et des conditions de gratuité du régime. Available from: http://www.ramq.gouv.qc.ca/fr/citoyens/assurance-medicaments/Pages/ tarifs vigueur.aspx.

4. Régie de l'assurance maladie du Québec. Assurance médicaments Montant à payer pour les médicaments. 2019 [cited 2019 2019-03-14]; Available from: http://www.ramq.gouv.qc.ca/fr/citoyens/assurancemedicaments/Pages/montant-a-payer-medicaments.aspx.

5. L'Association Québécoise des Pharmaciens Propriétaires, MÉMOIRE PRÉSENTÉ À LA COMMISSION DE LA SANTÉ ET DES SERVICES SOCIAUX, A.Q.d.P.P. (AQPP), Editor. 2016: Quebec. p. 58. Available from: https://aqppmonpharmacien-production.s3.ca-central-1.amazonaws.com/app/uploa ds/2020/02/05215240/Mémoire-AQPP PL31_02-10-2019.pdf.

6. Burkhart PV, Sabate E. Adherence to long-term therapies: evidence for action. J Nurs Scholarsh. 2003;35(3):207.

7. Heisler M, Wagner TH, Piette JD. Patient strategies to cope with high prescription medication costs: who is cutting back on necessities, increasing debt, or underusing medications? J Behav Med. 2005;28(1):43-51.

8. Murray A, Lyudmila G. Advancing the Responsible Use of Medicines: Applying Levers for Change (September 17, 2012). Available at SSRN: https://ssrn.com/abstract=2222541 or https://doi.org/10.2139/ssrn. 2222541.

9. Benefits Canada. Non-adherence costs employers. 2019 [cited 2019 18/09/2019]; Available from: https://www.benefitscanada.com/benefits/ health-benefits/non-adherence-costs-employers/.

10. Despres F, et al. Impact of drug plans on adherence to and the cost of antihypertensive medications among patients covered by a universal drug insurance program. Can J Cardiol. 2014:30(5):560-7.

11. Blais $L$, Kettani FZ, Forget A. PCV116 impact of the type of drug insurance on cost of statins and anti-depressants. Value Health. 2012;15(7):A383.

12. Desgagné M. Mémoire présenté à la comission des finances publiques dns le cadre des consultations particulières portant sur le projet de loi 28. Quebec; 2015. Available from: http://www.assnat.qc.ca/Media/Proce ss.aspx?Mediald=ANQ.Vigie.BII.DocumentGenerique_98635\&process= Default\&token=ZyMoxNwUn8ikQ+TRKYwPCjWrKwg+vlv9rjij7p3xLGT ZDmLVSmJLoqe/vG7/YWzz.

13. Le ministère de la Santé et des Services sociaux. Projet de loi visant à accroître les pouvoirs de la Régie de l'assurance maladie du Québec etmodifiant diverses dispositions législatives. RAMQ; 2016. p. 38. Available from: http://www.assnat.qc.ca/fr/travaux-parlementaires/projets-loi/ projet-loi-92-41-1.html.

14. Kapur V, Basu K. Drug coverage in Canada: who is at risk? Health Policy. 2005;71(2):181-93.

15. Gershon G. A REPORT OF THE ONTARIO CITIZENS' COUNCIL PRIVATE DRUG INSURANCE IN ONTARIO. 2012. Available from: https://www.health. gov.on.ca/en/public/programs/drugs/councils/docs/report_private_ drug_insurance_ontario.pdf.

16. The National Prescription Drug Utilization Information System. PRIVATE DRUG PLANS IN CANADA. 2015. Available from: https://www.canada.ca/ en/patented-medicine-prices-review/services/npduis/analytical-studies/ compassrx-6th-edition.html.

17. Adams AS, Soumerai SB, Ross-Degnan D. Use of antihypertensive drugs by Medicare enrollees: does type of drug coverage matter? Health Aff. 2001;20(1):276-86.

18. Poisal JA, Murray L. Growing differences between Medicare beneficiaries with and without drug coverage. Health Aff. 2001;20(2):74-85.

19. Blais L. REMED: REGISTRE DE DONNÉES SUR LES MÉDICAMENTS - UNIVERSITÉ DE MONTRÉAL. 2016 [cited 2019 18/10/2019]; Available from: https://www.rrcmdo.ca/ressources/remed-registre-de-donnees-sur-lesmedicaments/.

20. Blais L. REMED : DATA REGISTRY FOR PRESCRIBED MEDICATIONS / BANQUE DE DONNÉES SUR LES MÉDICAMENTS D'ORDONNANCE. 2016 [cited 2019 18/10/2019]; Available from: http://www.rarm.ca/plate formes/optimisation-de-l-usage/64-4-remed-data-registry-for-presc ribed-medications-banque-de-donnees-sur-les-medicaments-d-ordon nance.html.

21. L'Association Québécoise des Pharmaciens Propriétaires. COMPRENDRE VOTRE NOUVELLE FACTURE EN PHARMACIE. AQPP; 2017. Available from: 
https://aqpp-monpharmacien-production.s3.ca-central-1.amazonaws. com/app/uploads/2019/11/19210648/depliant_facture_detaillee_fr.pdf.

22. Régie de l'assurance maladie du Québec. Liste des médicaments de la RAMQ. 2019 [cited 2019 12/09/2019]; Available from: http://www.ramq. gouv.qc.ca/fr/publications/citoyens/publications-legales/Pages/listemedicaments.aspx.

23. Commissaire à la santé et au bien-être (CSBE). LES MÉDICAMENTS D'ORDONNANCE: ÉTAT DE LA SITUATION AU QUÉBEC. Quebec: 2014. p. 313. Available from: https://www.csbe.gouv.qc.ca/fileadmin/www/2014/ Medicaments/CSBE_Medicaments_EtatSituation_2e.pdf.

24. Régie de l'assurance maladie du Québec. Baisse du prix maximum payable (PMP) pour les médicaments de la classe des inhibiteurs de la pompe à protons (IPP). 2015 [cited 2019 18/10/2019]; Available from: http://www.ramq.gouv.qc.ca/SiteCollectionDocuments/professionnels/ infolettres/2015/info044-5.pdf.

25. Express Scripts Canada. ESI Canada Drug Trend Report. 2018. Available from: https://www.express-scripts.ca/sites/default/files/2020-12/Express_ Scripts_Canada_2018_Prescription_Drug_Trend_Report_FINAL.pdf.

26. Blais $L$, et al. PHP27 Comparison Of the use if prescribe medications between Quebec residents covered by publice and private drug insurance: the remed registry. Value in Health - VALUE HEALTH, 2010.

27. ESI Canada. Health Newsflash-Therapeutic Class Ranking (Top 100 Ranked by Claim Cost) Prescriptions filled from 01/2006 through 12/2006 compared to 01/2007 through 12/2007 Quebec. No. 2. 2008.10. Available from: http://www.esicanada.com/aboutus/news/health_newsflashes/ Volume_10_Issue2_TherapyClasses_Qc.pdf.

28. Després F. L'assurance médicaments et son impact sur l'adhésion des patients à leurs médicaments, in Faculty of Pharmacy. University of Montreal: Unviersity of Montreal; 2014. p. 168. Available from: https://papyrus. bib.umontreal.ca/xmlui/bitstream/handle/1866/13012/Despres_Franc ois 2014 memoire.pdf? sequence $=4$ \&is Allowed $=y$.

29. Le ministère de la Santé et des Services sociaux. Infocentre de santé publique à I'Institut national de santé publique du Québec. Indice de masse corporelle, selon le sexe. 2014 11/09/2019]; Available from: https:// www.msss.gouv.qc.ca/professionnels/statistiques-donnees-sante-bienetre/statistiques-de-sante-et-de-bien-etre-selon-le-sexe-volet-national/ indice-de-masse-corporelle/.

30. Le ministère de la Santé et des Services sociaux. Infocentre de santé publique à l'Institut national de santé publique du Québec. Évolution de la proportion de la population fumant actuellement, selon le sexe. 2014 [cited 2019 11/09/2019]; Available from: https://www.msss.gouv.qc.ca/ professionnels/statistiques-donnees-sante-bien-etre/statistiques-desante-et-de-bien-etre-selon-le-sexe-volet-national/population-fumantactuellement/.

\section{Publisher's Note}

Springer Nature remains neutral with regard to jurisdictional claims in published maps and institutional affiliations.

Ready to submit your research? Choose BMC and benefit from:

- fast, convenient online submission

- thorough peer review by experienced researchers in your field

- rapid publication on acceptance

- support for research data, including large and complex data types

- gold Open Access which fosters wider collaboration and increased citations

- maximum visibility for your research: over $100 \mathrm{M}$ website views per year

At BMC, research is always in progress.

Learn more biomedcentral.com/submissions 